• 研究报告・

\title{
新疆阿勒泰地区爬行动物区系及 多样性海拔分布格局
}

\author{
陶夏秋 ${ }^{1}$ 崔绍朋 2,3 蒋志刚 ${ }^{2,3}$ 初红军 4,5 李 娜, 3 杨道德 ${ }^{*}$ 李春旺 $2,3^{*}$ \\ 1 (中南林业科技大学野生动植物保护研究所, 长沙 410004) \\ 2 (中国科学院动物研究所, 北京 100101) \\ 3 (中国科学院大学, 北京 100049) \\ 4 (新疆卡拉麦里山有蹄类自然保护区阿勒泰管理站, 新疆阿勒泰 836500) \\ 5 (新疆大学资源与环境科学学院, 乌鲁木齐 830046)
}

摘要: 中国阿勒泰地区是北半球中纬度地区的特殊区域, 与俄罗斯、哈萨克斯坦、蒙古接壤, 境内有平原、沙漠 和山地三大地貌特征。2014-2016年, 我们先后3次对阿勒泰地区爬行动物资源开展了实地调查, 共采集到392号爬 行动物标本。经鉴定隶属1目6科16种, 结合文献资料, 共计1目8科23种, 均为古北界物种, 其中中亚型17种, 古北 型6种, 表现出中亚亚界与欧洲-西伯利亚亚界间的过渡性质。爬行动物Shannon-Wiener多样性指数、Simpson优势 度指数随海拔分布呈带有一个中峰的低海拔高原格局, 在第2海拔段 (500-600 m) 达到峰值; 均匀度指数总体呈现 递增格局, 第15海拔段 (1,800-1,900 m) 达到最大值; 丰富度则呈现一种波动的递减格局, 峰值在第10海拔段 $(1,300-1,400 \mathrm{~m})$ 。3 种环境因子对这种格局的独立解释力较低, 但综合作用的解释力较强, 其中海拔与年均温这两 个因子的综合作用对物种多样性影响程度最大。

关键词：阿勒泰地区; 爬行动物区系; 海拔梯度格局; 物种多样性; 环境因子

\section{Reptilian fauna and elevational patterns of the reptile species diversity in Altay Prefecture in Xinjiang, China}

\author{
Xiaqiu Tao ${ }^{1}$, Shaopeng Cui ${ }^{2,3}$, Zhigang Jiang ${ }^{2,3}$, Hongjun $\mathrm{Chu}^{4,5}, \mathrm{Na} \mathrm{Li}^{2,3}$, Daode Yang ${ }^{1 *}$, Chunwang $\mathrm{Li}^{2,3^{*}}$ \\ 1 Wildlife Protection Research Institute, Central South University of Forestry and Technology, Changsha 410004 \\ 2 Institute of Zoology, Chinese Academy of Sciences, Beijing 100101 \\ 3 University of Chinese Academy of Sciences, Beijing 100049 \\ 4 Altay Management Station of Mt. Kalamaili Ungulate Nature Reserve, Altay, Xinjiang 836500 \\ 5 College of Resources and Environment Science, Xinjiang University, Urumqi 830046
}

\begin{abstract}
The Altay Prefecture in China, which shares international boundaries with Kazakhstan, Mongolia and Russia, is a special area in the mid-latitudes of the Northern Hemisphere. The diverse landform of this area encompasses mountainous terrain, vast plains and desert lands. We conducted three expeditions from 2014 to 2016 to survey reptiles of the Altay Prefecture. We actively searched for reptiles using spotlighting at night. We collected a total of 392 specimens, which we identified as 16 species belonging to six families of the order Squamata. Combined with previous literature, the number of reptile species in this region is now 23 representing eight families of the order Squamata. All these species belong to the Palearctic ecozone, including 17 mid-Asia species versus six Palearctic species. From the geographical view, this region is a transitional zone between Euro-Siberian and Central-Asiatic regions. Next, we assessed how reptile species diversity correlated with elevation, which corresponded with changes in environmental factors in this region. We found that the Shannon-Wiener diversity index and Simpson dominance index showed a pattern of low-elevation plateaus with a mid-elevation peak, the Pielou evenness index showed a pattern of increasing, and the richness showed a pattern of decreasing. The peak values of Simpson dominance index and
\end{abstract}

收稿日期: 2018-05-08; 接受日期: 2018-05-26

基金项目: 国家科技基础性工作专项(2013FY110300)、国家重点研发计划项目(2016YFC0503304)和国家自然科学基金(31472021)

*共同通讯作者 Co-authors for correspondence. E-mails: csfuyydd@126.com; licw@ioz.ac.cn 
Shannon-Wiener diversity index were observed in Group 2 (500-600 m). The Pielou evenness index peaked for Group 15 (1,800-1,900 m), and richness peaked for Group 10 (1,300-1,400 m). The three environmental variables (altitude, annual mean temperature and annual precipitation) only weakly explained the observed patterns of diversity, richness and evenness, but their combined explanatory power was stronger. In fact, the combination of altitude and annual mean temperature best explained the observed patterns in diversity, richness and evenness of reptiles in the Altay Prefecture.

Key words: Altay Prefecture; herpetofauna; elevational pattern; species diversity; environmental variables

生物多样性沿海拔梯度的分布格局是其保护 研究的重要组成部分(Vetaas \& Grytnes, 2002)。过去 认为物种多样性随纬度和海拔梯度的增加而呈现 单调递减模式(monotonically decreasing), 但20世纪 中期人们发现动植物物种更多地表现出随海拔的 升高, 丰富度呈中峰模式(mid-elevation peak), 即中 海拔段物种丰富度较高(Whittaker, 1960; Whittaker \& Niering, 1965; Brown, 1971; Lomolino, 2001)。 Rahbek (1995)通过对全球不同区域动植物物种海 拔分布格局的分析, 认为除了单调递减、单峰分布 格局这 2 种常见模式外, 还有一种低海拔带出现一 个高的平台, 然后下降的模式也较为常见, 即先平 台后递减(horizontal, then decreasing)。其中: 单调递 减在样本中占有 $21 \%$ 、中峰分布占 $49 \%$ 、先平台后 递减占24\%。McCain (2010)利用 $10.3^{\circ}-46.1^{\circ} \mathrm{N}$ 山地 的爬行动物海拔分布数据, 分析了全球爬行动物多 样性海拔分布格局, 发现爬行动物物种沿海拔梯度 分布基本呈现4种模式: 递减模式(decreasing patterns)、低海拔高原模式(low-elevation plateaus, LP)、 带有一个中峰格局的低海拔高原模式(low-elevation plateaus with a mid-elevation peak, LPMP)、中峰模式 (mid-elevation peak, MP), 这4种分布模式分别占 $54 \% 、 21 \% 、 4 \%$ 和 $21 \%$ 。Lomolino (2001)认为物种 多样性与海拔梯度分布规律很大程度上依赖于环 境变量之间的相互作用。因此, 关于不同类群物种 多样性海拔格局的研究, 对阐明物种多样性与海拔 梯度的关系具有重要价值。

对于物种多样性海拔分布格局形成的原因, 人 们进行了多方面探讨, 但仍未找出一个与之最相关 的环境因子和最具说服力的假说, 能量假说(包括 生产力、温度、湿度、降水、蒸散作用等)是其中一 种讨论较多的假说(吴永杰和雷富民, 2013)。该假说 认为, 植物生产力高、温度高、湿度高、降水丰富、 蒸散作用强烈的地区, 物种多样性就越高; 而植物
生产力低、温度低、湿度低、降水稀少、蒸散作用 弱的地区，物种多样性则较低。Kessler (2000)发现 颜类和野牡丹科植物物种多样性主要与湿度相关, 而爵床科植物和风梨科植物物种多样性与海拔(温 度)相关, 天南星科植物物种多样性则与潜在蒸腾 相关等; Wu等(2013)发现贡嘎山地区的非特有小型 兽类物种多样性与温度相关。相对其他脊椎动物类 群, 爬行动物的地理分布更容易受水分(湿度、降雨 量)和能量(温度)的限制(Qian et al, 2007; Qian, 2010)。

阿勒泰地区包括阿尔泰山南麓和准噶尔盆地 北缘, 是一个以森林、荒漠为主体的复合生态系统。 该地区爬行动物的早期研究资料散见于Zhao 和 Adler (1993)、赵肯堂(1979、1983、1997、1998)等 著作中。20世纪80年代以来, 学者们相继开展了针 对爬行动物物种的调查工作(王国英等, 2005; 时否 等, 2006)。许设科等(1980)、周永恒等(1986)报道了 2 个新记录种。时否等(2002)对新疆地区爬行动物的 研究中, 首次涉及了阿勒泰地区爬行动物的动物区 系与地理区划。该区域爬行动物最近的调查数据见 于刘晏良(2010)关于北屯-布尔津-哈巴河线的动物 调查工作。为掌握阿勒泰地区爬行动物生物多样性 及区系特征, 维护国家安全和保障边疆地区经济社 会可持续发展，我们于2014年6月至2016年9月, 共 3次对阿勒泰地区爬行动物资源进行了系统考察, 研究了阿勒泰地区不同海拔梯度下爬行动物的物 种多样性, 以及年降水量、年均温、海拔的变化对 爬行动物物种多样性的影响, 探索了爬行动物在不 同海拔梯度下分布差异的原因。

\section{研究区域概况}

中国阿勒泰地区是北半球中纬度地区的特殊 地区, 东部与蒙古国接壤, 西部、北部与哈萨克斯 坦、俄罗斯交界, 西南部以萨吾尔山山脊线接乌伦 
古湖南岸草原同塔城地区毗连, 南部属古尔班通古 特沙漠, 与昌吉州交界, 面积约117,988 $\mathrm{km}^{2}$ 。由于 受纬度和地形影响, 阿勒泰地区具有春季多风, 夏 季短暂气温平和, 秋季凉爽, 冬季寒冷漫长的气候 特点，属温带大陆性气候。

阿勒泰地区的大部分植被种类集中在阿尔泰 山地, 具有十分丰富的针叶林资源, 主要有西伯利 亚云杉(Picea obovata)、冷杉(Abies fabri)、红松 (Pinus koraiensis)、杨树 (Populus spp.)和白桦(Betula platyphylla)等珍贵树种。阿尔泰山还具有特殊的植 被垂直带谱结构，800-1,300 $\mathrm{m}$ 为灌木草原带; 1,300-2,600 m是森林草原带; 2,600-3,500 m是高山 -亚高山草甸草原带; 3,000 m以上永久积雪, 分布 少量的苔藓植物。河谷森林以杨树与白桦为主。位 于前山的河谷有黑杨(Populus nigra)-苦杨(P. laurifolia)天然杂交次生林、银白杨(P. alba)天然次生林 和全国唯一的银灰杨 (P. canescens) 天然次生林, 具 有很高的观赏价值与科学参考价值。

除阿尔泰山地外，阿勒泰地区拥有大面积的荒
漠，这些地区的植物群落组成相对简单，由碱韭 (Allium polyrhizum)、沙蒿 (Artemisia desertorum)、木 苶(Atraphaxis frutescens)、蒙古沙拐菄(Calligonum mongolicum)、角果藜(Ceratocarpus arenarius)、驼 线僽(Ceratoides latens)、梭梭(Haloxylon ammodendron)、细少 (Reaumuria soongarica) 和沙生针茅(Stipa glareosa)等耐寒、耐旱、耐风沙的荒漠植物组成。

\section{2 研究方法}

\section{1 调查时间与方法}

我们分别于2014年6-7月，2015年8-9月和2016 年7-9月对阿勒泰地区的爬行动物开展了 3 次调查。 调查前，综合考虑阿勒泰地区的地形、地貌、植被 与爬行动物的生态习性, 选择26个代表性强的样区 进行调查(图1)。

在每个样区采用样线法进行数据采集，同时辅 以样方法、访问调查法和专项调查法，搜索由 1 组 2-3人进行, 行进时相对速度保持 $1-2 \mathrm{~km} / \mathrm{h}$ 。在调查 区域内，采取目视遇测法搜索爬行动物信息，包括

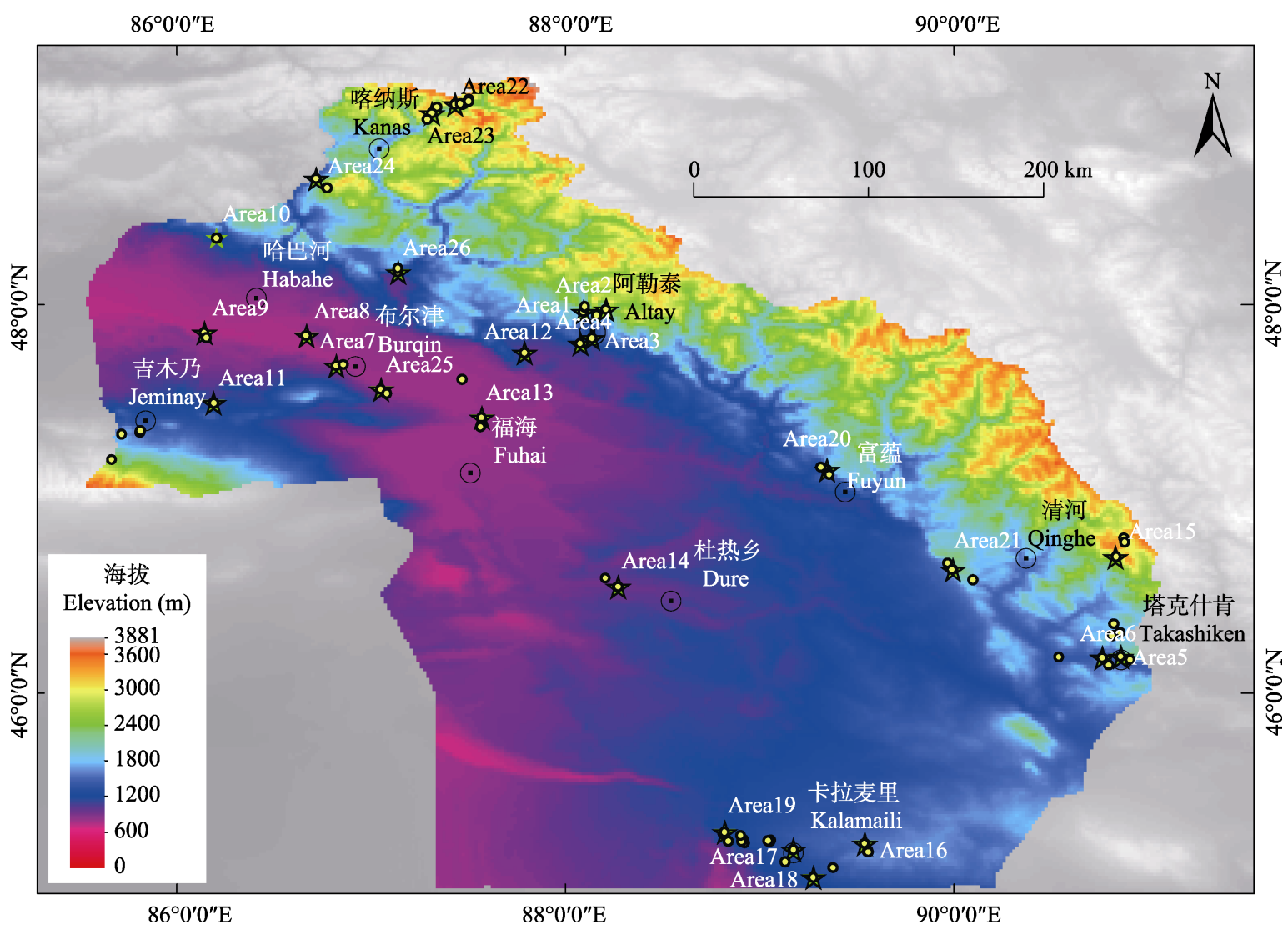

图1 新疆阿勒泰地区爬行动物调查样区分布示意图

Fig. 1 Demonstration map of sample areas in Altay Prefecture 
动物实体(活体和尸体)、痕迹。对灌从、人工林和 水域等地区展开样线调查, 同时对生境较适宜的区 域辅以样方调查。发现爬行动物后, 在野外鉴定并 拍下活体照片, 记录发现地点的地理坐标等数据。对 每一物种进行个体标本采集, 用 $98 \%$ 酒精保存。对不 需要做标本的个体，在物种辨认测量后原地释放。

同时对当地居民进行访问调查，并通过工具书 来鉴定与核实访问到的物种。动物鉴定参考季达明 和温世生(2002), 分类系统参考蔡波等(2015); 地理
区划参考张荣祖(2011); 受胁状况参考蒋志刚等 (2016)。

\section{2 数据分析}

调查结果显示, 阿勒泰地区爬行动物主要分布 在477-1,988 m海拔段(表1)。在2015年8月9日于蒙 其克人工沙棘林 $2,272 \mathrm{~m}$ 处仅发现 1 只旱地沙蚚 (Phrynocephalus heliocopus), 因此, 我们将该地 400-2,000 m的海拔按照 $100 \mathrm{~m}$ 的间隔划分成 16 个海 拔段。统计每个海拔段内的物种数。

\section{表1 阿勒泰地区26个样区爬行动物调查结果}

Table 1 Result of reptile survey of 26 sample areas in Altay Prefecture

\begin{tabular}{|c|c|c|c|}
\hline $\begin{array}{l}\text { 样区 } \\
\text { Sample } \\
\text { area }\end{array}$ & $\begin{array}{l}\text { 海拔区间 } \\
\text { Altitude } \\
\text { range (m) }\end{array}$ & $\begin{array}{l}\text { 经纬度 } \\
\text { Longitude and } \\
\text { latitude }\end{array}$ & $\begin{array}{l}\text { 物种* } \\
\text { Species* }\end{array}$ \\
\hline 1 & $1,100-1,200$ & $47.96^{\circ} \mathrm{N}, 88.09^{\circ} \mathrm{E}$ & 捷蜘蜴(2)、极北蛏(2) Lacerta agilis (2), Vipera berus (2) \\
\hline 2 & $1,300-1,400$ & $47.98^{\circ} \mathrm{N}, 88.21^{\circ} \mathrm{E}$ & 密点麻蜥(3) Eremias multiocellata (3) \\
\hline 3 & $800-900$ & $47.83^{\circ} \mathrm{N}, 88.14^{\circ} \mathrm{E}$ & 捷蜘蜴(5) Lacerta agilis (5) \\
\hline 4 & $900-1,000$ & $47.89^{\circ} \mathrm{N}, 88.08^{\circ} \mathrm{E}$ & 快步麻蚚(4) Eremias velox (4) \\
\hline 5 & $1,100-1,200$ & $46.19^{\circ} \mathrm{N}, 90.86^{\circ} \mathrm{E}$ & $\begin{array}{l}\text { 奇台沙蜊(4)、旱地沙蚚(30)、变色沙蚚(2)、密点麻蜘(2) Phrynocephalus grumgrzimailoi (4), } \\
\text { Phrynocephalus helioscopus (30), Phrynocephalus versicolor (2), Eremias multiocellata (2) }\end{array}$ \\
\hline 6 & $1,200-1,300$ & $46.18^{\circ} \mathrm{N}, 90.76^{\circ} \mathrm{E}$ & 新疆岩蜊(3)、早地沙蜥(2) Laudakia stoliczkana (3), Phrynocephalus helioscopus (2) \\
\hline 7 & $500-600$ & $47.69^{\circ} \mathrm{N}, 86.82^{\circ} \mathrm{E}$ & $\begin{array}{l}\text { 奇台沙蜘(8)、快步麻蚚(2)、密点麻蜊(4)、㧼虾蜴(2) Phrynocephalus grumgrzimailoi (8), Eremias } \\
\text { velox (2), Eremias multiocellata (4), Lacerta agilis (2) }\end{array}$ \\
\hline 8 & $400-500$ & $47.84^{\circ} \mathrm{N}, 86.67^{\circ} \mathrm{E}$ & 奇台沙蜊(12) Phrynocephalus grumgrzimailoi (12) \\
\hline 9 & $400-500$ & $47.86^{\circ} \mathrm{N}, 86.14^{\circ} \mathrm{E}$ & 奇台沙蜘(6)、虫纹麻蜥(1) Phrynocephalus grumgrzimailoi (6), Eremias vermiculata (1) \\
\hline 10 & $800-900$ & $48.34^{\circ} \mathrm{N}, 86.21^{\circ} \mathrm{E}$ & 捷蜘蜴(8) Lacerta agilis (8) \\
\hline 11 & $800-900$ & $47.49^{\circ} \mathrm{N}, 86.19^{\circ} \mathrm{E}$ & 捷蜥蜴(6) Lacerta agilis (6) \\
\hline 12 & $700-800$ & $47.75^{\circ} \mathrm{N}, 87.79^{\circ} \mathrm{E}$ & 捷蚚蜴(4)、黄脊东方蛇(2) Lacerta agilis (4), Orientocoluber spinalis (2) \\
\hline 13 & $400-500$ & $47.42^{\circ} \mathrm{N}, 87.57^{\circ} \mathrm{E}$ & 旱地沙蜘(6)、敏麻蚚(2) Phrynocephalus helioscopus (6), Eremias arguta (2) \\
\hline 14 & $600-700$ & $46.55^{\circ} \mathrm{N}, 88.27^{\circ} \mathrm{E}$ & 旱地沙蚚(2)、快步麻䖵(6) Phrynocephalus helioscopus (2), Eremias velox (6) \\
\hline 15 & $900-1,000$ & $46.70^{\circ} \mathrm{N}, 90.83^{\circ} \mathrm{E}$ & 奇台沙蜓(15)、早地沙蜓(3) Phrynocephalus grumgrzimailoi (15), Phrynocephalus helioscopus (3) \\
\hline 16 & $1,200-1,300$ & $45.22^{\circ} \mathrm{N}, 89.54^{\circ} \mathrm{E}$ & 旱地沙蜥(2)、红沙蟒(1) Phrynocephalus helioscopus (2), Eryx miliaris (1) \\
\hline 17 & $1,300-1,400$ & $45.19^{\circ} \mathrm{N}, 89.17^{\circ} \mathrm{E}$ & $\begin{array}{l}\text { 早地沙蚘(6)、虫纹麻蜥(1)、快步麻蚚(2)、奇台沙蚚(3) Phrynocephalus helioscopus (6), Eremias } \\
\text { vermiculata (1), Eremias velox (2), Phrynocephalus grumgrzimailoi (3) }\end{array}$ \\
\hline 18 & $900-1,000$ & $45.05^{\circ} \mathrm{N}, 89.28^{\circ} \mathrm{E}$ & 旱地沙蜥(20) Phrynocephalus helioscopus (20) \\
\hline 19 & $900-1,000$ & $45.28^{\circ} \mathrm{N}, 88.82^{\circ} \mathrm{E}$ & 奇台沙蚚(21) Phrynocephalus grumgrzimailoi (21) \\
\hline 20 & $900-1,000$ & $47.15^{\circ} \mathrm{N}, 89.35^{\circ} \mathrm{E}$ & 旱地沙蜘(25) Phrynocephalus helioscopus (25) \\
\hline 21 & $900-1,000$ & $46.63^{\circ} \mathrm{N}, 89.99^{\circ} \mathrm{E}$ & 奇台沙蜘(2)、旱地沙蚚(4) Phrynocephalus grumgrzimailoi (2), Phrynocephalus helioscopus (4) \\
\hline 22 & $1,700-1,800$ & $49.03^{\circ} \mathrm{N}, 87.43^{\circ} \mathrm{E}$ & 极北蛙(9)、捷蜊蜴(2) Vipera berus (9), Lacerta agilis (2) \\
\hline 23 & $1,500-1,600$ & $48.99^{\circ} \mathrm{N}, 87.31^{\circ} \mathrm{E}$ & 极北蝰(4)、捷蚚蜴(2)、胎蜊(1) Vipera berus (4), Lacerta agilis (2), Zootoca vivipara (1) \\
\hline 24 & $1,300-1,400$ & $48.65^{\circ} \mathrm{N}, 86.72^{\circ} \mathrm{E}$ & 敏麻蜊(1)、极北蝰(1)、隐耳漠虎(3) Eremias arguta (1), Vipera berus (1), Alsophylax pipiens (3) \\
\hline 25 & $500-600$ & $47.56^{\circ} \mathrm{N}, 87.05^{\circ} \mathrm{E}$ & 敏麻蜘(1)、旱地沙蜊(2) Eremias arguta (1), Phrynocephalus helioscopus (2) \\
\hline 26 & $700-800$ & $48.17^{\circ} \mathrm{N}, 87.14^{\circ} \mathrm{E}$ & 白条锦蛇(1)、旱地沙蚚(3) Elaphe dione (1), Phrynocephalus helioscopus (3) \\
\hline
\end{tabular}


采用Shannon-Wiener指数、Pielou均匀度指数、 修正后的Simpson优势度指数和物种丰富度对 26 个 样区及 16 个海拔段的爬行动物物种多样性进行测 度(张金屯, 2004), 公式为:

Shannon-Wiener指数: $H=-\sum_{i=1}^{S}\left(p_{i}\right)\left(\ln p_{i}\right)$

Pielou均匀度指数: $R=H / \ln S$

修正后的Simpson优势度指数:

$$
D=-\ln \sum_{i=1}^{S}\left(p_{i}\right)^{2}
$$

物种丰富度: $P=S$

式中, $S$ 是记录到的物种总数, $p_{i}$ 为物种 $i$ 的个体数占 所有物种个体数之比。

本研究利用的气候数据包括年均温 (annual mean temperature, AMT)和年降水量(annual precipitation, AP) 2种, 这些数据来自世界气候数据网站 (http://www.worldclim.org), 数据精度为 $1 \mathrm{~km}^{2}$ 。我门 利用ArcGIS 10.2软件对所有网格重采样, 使每个调 查样区都在栅格内(精度为 $10 \mathrm{~km}^{2}$ )。

广义加合模型 (generalized additive model, GAM) 是用环境变量的高阶多项式来拟合种与环境 变量的关系(朱源和康慕谊, 2005), 其假设函数是相 加的, 函数的组成为光滑函数(smooth functions)(温 仲明等, 2008)。由于它没有预先设定变量之间的关 系, 而是通过环境变量的光滑函数代替回归系数的 功能, 所以能最大程度符合原始数据的规律 (吴裕 鹏等, 2013), 而且数据中的非线性关系, 如双峰和 不对称现象很容易被发现(曹铭昌等, 2005)。其基本 模型如下:

$$
F(X)=f_{1}\left(x_{1}\right)+f_{2}\left(x_{2}\right)+\cdots+f_{p}\left(x_{p}\right)+b_{0}
$$

式中, $F(X)$ 为连接函数; $b_{0}$ 为截距; $f_{1}, f_{2} \ldots f_{p}$ 为 $p$ 个环 境变量 $X$ 的光滑函数。

本研究中, 运用GAM对爬行动物物种多样性 沿海拔的分布格局及各样区内爬行动物物种多样 性的各影响因子进行拟合。并绘制沿海拔梯度的物 种多样性分布图及海拔、年降水量和年均温3种环 境因子对物种多样性的影响。物种多样性分布图以 物种多样性指数为因变量, 以海拔梯度为自变量。

本研究中, 所有统计分析均在 $\mathrm{R}$ 软件中进行, 加载mgcv软件包中的 gam命令(Wood, 2017), $P<$ 0.05 为差异显著。

\section{结果}

\section{1 物种组成}

本次野外实际记录爬行动物标本392号, 均属 有鳞目，共计 6 科 10 属 16 种，结合文献资料，该区共 计分布有 1 目 8 科 23 种(附录1)。其中蜊蜴亚目占优势, 有 4 科 13 种，又以蝰蜴科种类最多，共有 6 种。阿勒 泰地区爬行动物均属古北界, 其中中亚型17种, 古 北型6种。

\section{2 多样性指数随海拔的变化}

爬行动物的 Shannon-Wiener多样性指数、 Simpson优势度指数的海拔梯度格局均呈带有一个 中峰的低海拔高原格局，均在第2海拔段(500-600 m) 达到最大值，而后虽然在第10海拔段(1,300-1,400 m) 会产生峰值，但低于之前的高平台(图2A, B); Pielou 均匀度指数的海拔梯度格局总体呈现递增格局, 在 第5海拔段(800-900 m) 前呈现递减趋势，在第5海 拔段(800-900 m) 后呈现递增趋势, 最终在第15海 拔段(1,800-1,900 m)达到最大值(图2C); 丰富度的 海拔梯度格局则呈现一种波动的递减格局, 虽然模 型预测的趋势为单调递减，但在第 2 海拔段 (500-600 m)后，丰富度呈降-升-降的趋势，第三次 数值变化最大，丰富度的峰值在第 10 海拔段 (1,300-1,400 m)(图2D)。

\section{3 环境因子的解释}

采用AIC信息标准进行最优模拟，结果表明海 拔、年均温进入阿勒泰地区爬行动物的多样性指 数、优势度指数、丰富度的最优模型，除优势度指 数外, 多样性指数、丰富度与 2 种环境因子相关性显 著 (海拔: $P$ 多样性 $=0.004325<0.01, P_{\text {优势度 }}=0.109>$ $0.05, P_{\text {丰富度 }}=0.00473<0.01$; 年均温 $: P_{\text {多样性 }}=$ $0.000831<0.001, P_{\text {优势度 }}=0.239>0.05, P_{\text {丰富度 }}=$ $0.00525<0.01)$; 而年降水量未进入优势度指数的 最优模型, 且只与丰富度相关性极显著 $(P$ 多样性 $=$ $\left.0.097212>0.05, P_{\text {丰富度 }}=0.00973<0.01\right)$ 。单独因子 方面, 海拔、年均温、年降水量这 3 种因子在单独对 阿勒泰地区爬行动物的多样性指数、优势度指数、 丰富度方面的解释力较差, AIC值较高。海拔对多样 性指数及优势度指数影响程度最高, 分别为 $45.9 \%$ 及 $43.6 \%$, 但是对优势度指数的影响并不显著 $(P=$ $0.0542>0.05)$; 而年降水量对丰富度影响度最高, 为 $44.8 \%$, 但不显著 $(P=0.095>0.05)$ 。两 


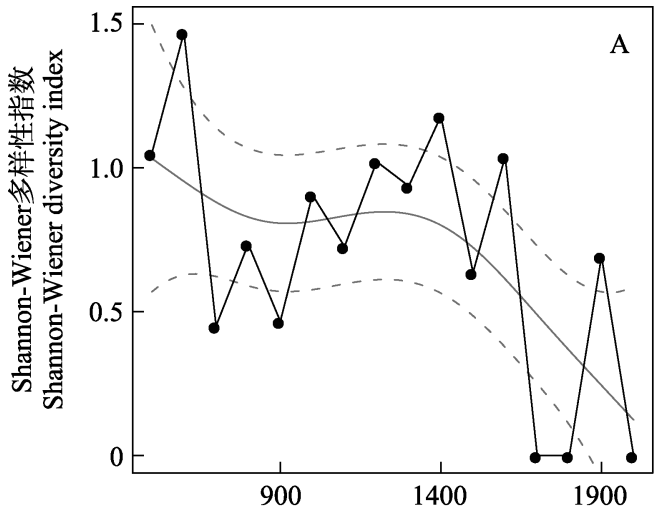

海拔 Elevation (m)

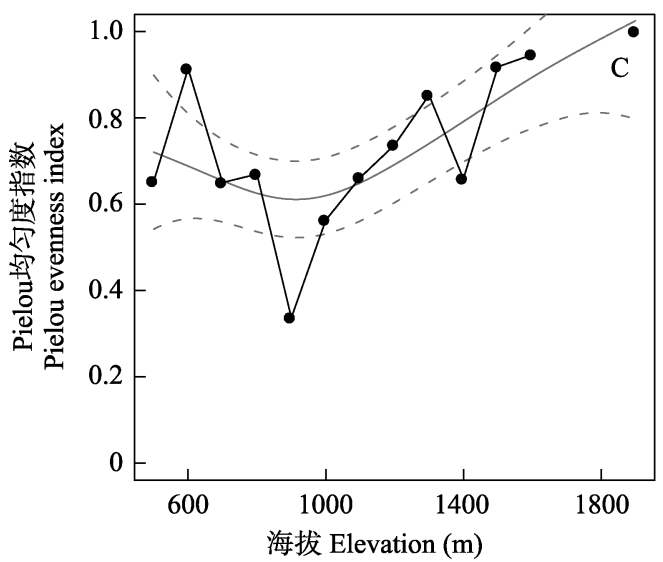

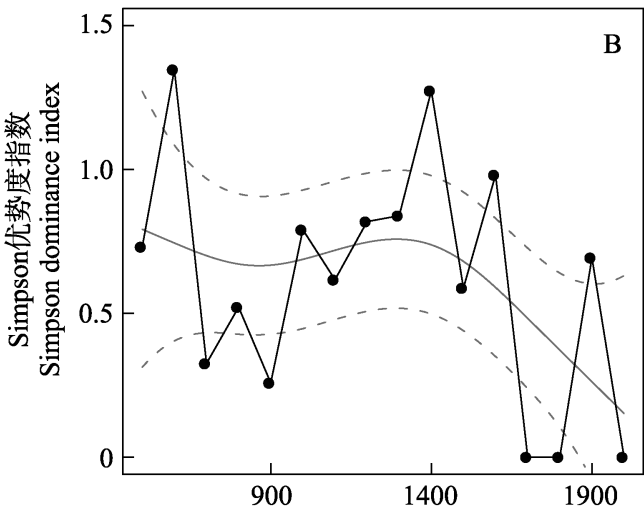

海拔 Elevation (m)

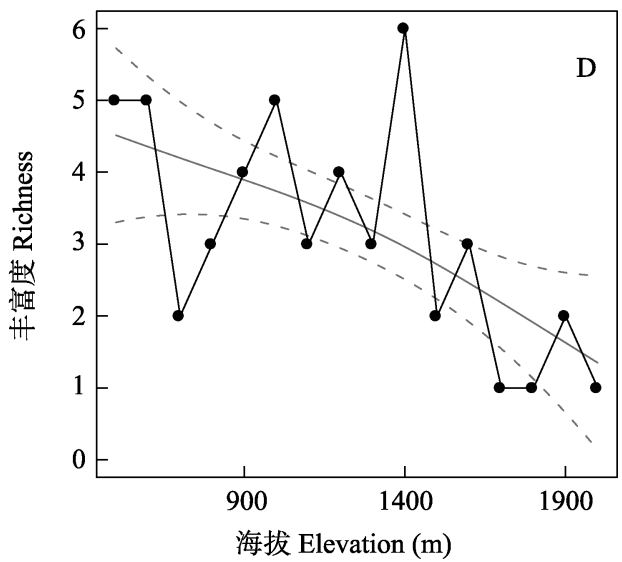

图2 爬行动物物种多样性随海拔梯度的变化。实点表示观测的物种多样性, 灰色实线为模型预测的物种多样性, 灰色虚线表 示模型预测的 $95 \%$ 置信区间。

Fig. 2 Change of reptile species diversity along the elevational gradient. Dot represents observed species diversity. Grey solid line represents the predicted diversity by model. Dashed grey lines represent $95 \%$ confident intervals of predicted diversity.

个因子方面, 海拔、年均温组合为优势度指数的最 优模型, 但对丰富度的解释力最弱, 为 $35.1 \%$, 且 2 个环境因子的影响均不显著 $\left(P_{\text {年均温 }}=0.130, P_{\text {海拔 }}=\right.$ $0.288) ;$ 年降水量、年均温组合在多样性指数、优势 度指数方面影响程度为最弱, 分别为 $18.5 \%$ 、 $17.3 \%$ 、 $24.8 \%$, 且 2 个环境因子的影响均不显著(年降水量: $P_{\text {多样性 }}=0.5127>0.05, P_{\text {丰富度 }}=0.328>0.05$; 年均温: $\left.P_{\text {多样性 }}=0.0562>0.05, P_{\text {丰富度 }}=0.103>0.05\right)($ 表 2$)$ 。

\section{4 环境因子的影响}

通过对年均温、海拔与爬行动物的多样性指 数、优势度指数、丰富度建立GAM模型, 并得到环 境因子对多样性影响效应图(如图3-5)。

Shannon-Wiener多样性指数: 三种环境因子与 多样性指数均呈负相关, 其中年均温、海拔与多样 性指数为线性关系, 年降水量则与多样性指数近似 线性 $\left(v_{\text {年均温 }}=v_{\text {海拔 }}=1, v_{\text {年降水量 }}=1.75\right.$, 图3 $)$ 。

Simpson优势度指数: 两种环境因子中, 年均
温与优势度指数为线性关系，且呈负相关; 海拔与 优势度指数呈复杂非线性关系, 整体表现是随着海 拔的增加, 优势度呈降低趋势 $\left(v\right.$ 年均温 $=1, v_{\text {海拔 }}=4.65$, 图4)。其中在400-486.5 m范围内, 优势度随海拔的 上升而变大; 在486.5-909 m范围内, 优势度随海拔 升高而变小; 在约909-1,263 m范围内, 优势度表现 为单调递增, 当大于 $1,263 \mathrm{~m}$ 后, 优势度表现为单调 递减(图4B)。

丰富度: 三种环境因子中, 年均温、海拔与丰富 度为线性关系，且呈负相关 $\left(v\right.$ 年均温 $=v_{\text {海拔 }}=1$, 图 $5 \mathrm{~A}$, 5B)。年降水量与丰富度变化表现为非线性，整体表 现是随着年降水量的增加, 优势度呈降低趋势, 在 小于 $237 \mathrm{~mm}$ 区间内，随着年降水量的增加，丰富度 呈递减趋势; 当降水量在约237-300 mm范围内, 随 着年降水量的增加，丰富度呈递增趋势; 而在约 300-351 mm范围内, 年降水量与丰富度呈反比; 大 于351 mm区间内, 年降水量与丰富度呈正比(图5C)。 
表2 阿勒泰地区爬行动物多样性指数与不同因子的广义相加模型

Table 2 Generalized additive models for the species diversity of reptiles in Altay Prefecture

\begin{tabular}{|c|c|c|c|c|}
\hline 变量 Variables & $\begin{array}{l}\text { 模型解释力 } \\
\text { Explanatory power }\left(R^{2}, \%\right)\end{array}$ & AIC & $P$ & $\begin{array}{l}\text { 自由度 } \\
\text { Effective degrees of freedom }\end{array}$ \\
\hline \multicolumn{5}{|c|}{ Shannon-Wiener多样性指数 Shannon-Wiener diversity index } \\
\hline 海拔 Altitude & 45.9 & 19.57 & $0.040^{*}$ & 4.30 \\
\hline 年均温 $\mathrm{AMT}$ & 17 & 24.10 & $0.036^{*}$ & 1 \\
\hline 年降水量 AP & 4.39 & 27.81 & $0.00013^{* * *}$ & 0.34 \\
\hline 海拔 $\times$ 年降水量 Altitude $\times$ AP & 51.1 & 20.16 & $P_{\text {Altitude }}=0.050^{*} ; P_{\mathrm{AP}}=0.78$ & $v_{\text {Altitude }}=4.64 ; v_{\mathrm{AP}}=1.28$ \\
\hline 年降水量 $\times$ 年均温 $\mathrm{AP} \times \mathrm{AMT}$ & 18.5 & 25.04 & $P_{\mathrm{AMT}}=0.056 ; P_{\mathrm{AP}}=0.51$ & $v_{\mathrm{AMT}}=1 ; v_{\mathrm{AP}}=1$ \\
\hline 海拔 $\times$ 年均温 Altitude $\times$ AMT & 52.4 & 25.61 & $P_{\mathrm{AMT}}=0.23 ; P_{\text {Altitude }}=0.091$ & $v_{\mathrm{AMT}}=1 ; v_{\mathrm{Altitude}}=4.62$ \\
\hline $\begin{array}{l}\text { 海拔 } \times \text { 年降水量 } \times \text { 年均温 } \\
\text { Altitude } \times \mathrm{AP} \times \mathrm{AMT}\end{array}$ & 47.1 & 17.89 & $\begin{array}{l}P_{\mathrm{AMT}}=0.00083^{* * *} ; \\
P_{\text {Altitude }}=0.0043^{* * *} ; P_{\mathrm{AP}}=0.097\end{array}$ & $v_{\mathrm{AMT}}=1 ; v_{\text {Altitude }}=1 ; v_{\mathrm{AP}}=1.75$ \\
\hline \multicolumn{5}{|c|}{ Simpson优势度指数 Simpson dominance index } \\
\hline 海拔 Altitude & 43.6 & 13.38 & 0.054 & 4.12 \\
\hline 年均温 AMT & 16.2 & 17.27 & $0.042^{*}$ & 1 \\
\hline 年降水量 AP & 4.49 & 20.66 & 0.30 & 1 \\
\hline 海拔 $\times$ 年降水量 Altitude $\times \mathrm{AP}$ & 49.1 & 13.93 & $P_{\text {Altitude }}=0.061 ; P_{\mathrm{AP}}=0.68$ & $v_{\text {Altitude }}=4.82 ; v_{\mathrm{AP}}=1.00$ \\
\hline 年降水量 $\times$ 年均温 $\mathrm{AP} \times \mathrm{AMT}$ & 17.3 & 18.92 & $P_{\mathrm{AMT}}=0.072 ; P_{\mathrm{AP}}=0.58$ & $v_{\mathrm{AMT}}=1 ; v_{\mathrm{AP}}=1$ \\
\hline 海拔 $\times$ 年均温 Altitude $\times$ AMT & 51 & 12.62 & $P_{\text {AMT }}=0.24 ; P_{\text {Altitude }}=0.11$ & $v_{\mathrm{AMT}}=4.65 ; v_{\text {Altitude }}=1$ \\
\hline $\begin{array}{l}\text { 海拔 } \times \text { 年降水量 } \times \text { 年均温 } \\
\text { Altitude } \times \mathrm{AP} \times \mathrm{AMT}\end{array}$ & 40.1 & 13.42 & $\begin{array}{l}P_{\mathrm{AMT}}=0.0023^{* *} ; P_{\text {Altitude }}=0.011^{*} ; \\
P_{\mathrm{AP}}=0.18\end{array}$ & $v_{\mathrm{AMT}}=1 ; v_{\text {Altitude }}=1 ; v_{\mathrm{AP}}=1.45$ \\
\hline \multicolumn{5}{|l|}{ 丰富度 Richness } \\
\hline 海拔 Altitude & 36.5 & 63.08 & 0.096 & 3.67 \\
\hline 年均温 AMT & 17.7 & 64.49 & $0.033^{*}$ & 1.01 \\
\hline 年降水量 AP & 44.8 & 62.89 & 0.095 & 5.38 \\
\hline 海拔 $\times$ 年降水量 Altitude $\times \mathrm{AP}$ & 65.4 & 55.55 & $P_{\text {Altitude }}=0.14 ; P_{\mathrm{AP}}=0.022^{*}$ & $v_{\text {Altitude }}=2.06 ; v_{\mathrm{AP}}=5.73$ \\
\hline 年降水量 $\times$ 年均温 $\mathrm{AP} \times \mathrm{AMT}$ & 37.3 & 63.77 & $P_{\mathrm{AMT}}=0.10 ; P_{\mathrm{AP}}=0.33$ & $v_{\mathrm{AMT}}=1.00 ; v_{\mathrm{AP}}=3.17$ \\
\hline 海拔 $\times$ 年均温 Altitude $\times$ AMT & 35.1 & 63.50 & $P_{\mathrm{AMT}}=0.13 ; P_{\text {Altitude }}=0.29$ & $v_{\mathrm{AMT}}=1.00 ; v_{\text {Altitude }}=2.60$ \\
\hline $\begin{array}{l}\text { 海拔 } \times \text { 年降水量 } \times \text { 年均温 } \\
\text { Altitude } \times \mathrm{AP} \times \mathrm{AMT}\end{array}$ & 69.6 & 51.72 & $\begin{array}{l}P_{\mathrm{AMT}}=0.0053^{* *} ; \\
P_{\text {Altitude }}=0.0047^{* *} ; P_{\mathrm{AP}}=0.0097^{* *}\end{array}$ & $\begin{array}{l}v_{\mathrm{AMT}}=1.00 ; v_{\text {Altitude }}=1.00 \\
v_{\mathrm{AP}}=5.57\end{array}$ \\
\hline
\end{tabular}

AMT, Annual mean temperature; AP, Annual precipitation.

* $P<0.05$; ** $P<0.01$; *** $P<0.001$.
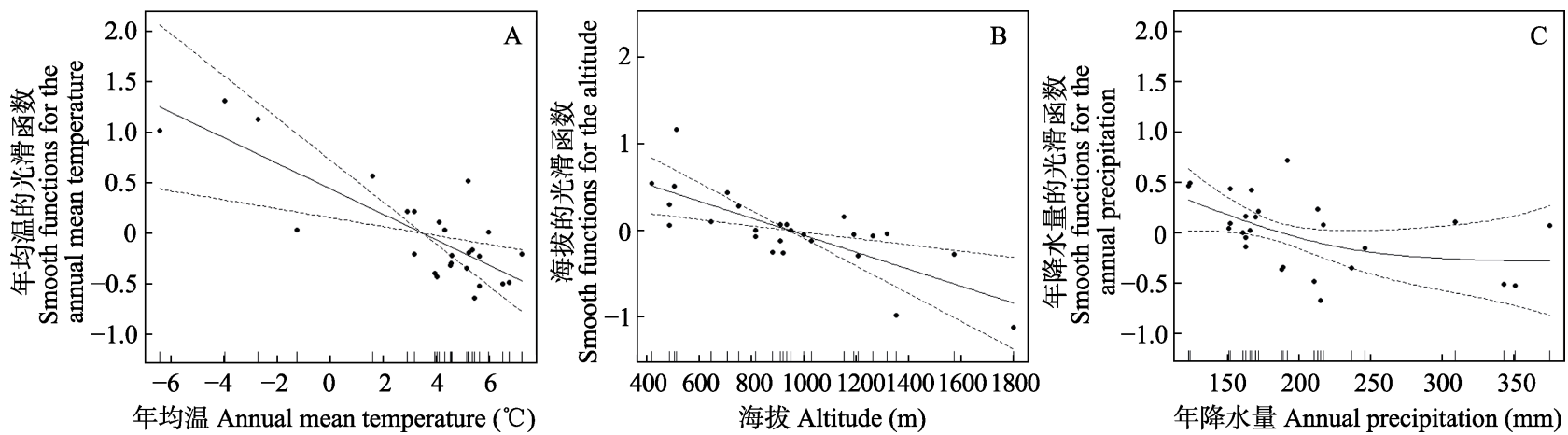

图3 Shannon-Wiener多样性指数的最优模型环境因子光滑函数拟合结果。实点表示观测的多样性指数, 实线为模型预测的 拟合曲线，虚线表示模型预测的 $95 \%$ 置信区间。纵坐标为环境因子的光滑函数，表示其对Shannon-Wiener多样性指数的影响 程度。

Fig. 3 Results of GAM analysis on Shannon-Wiener diversity index. Dot represents observed diversity index. Solid line represents the predicted fitting curves by model. Dashed lines represent $95 \%$ confident intervals of predicted diversity. Ordinate is smooth function for environmental variables, represents their impact on Shannon-Wiener diversity index. 

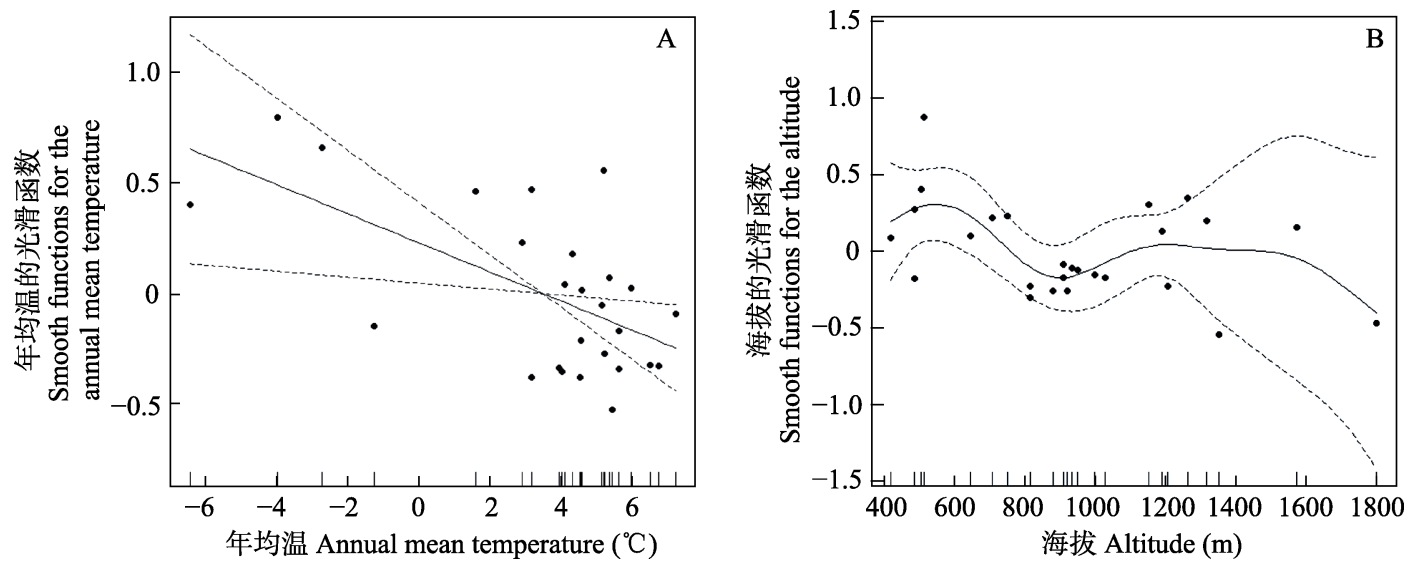

图4 Simpson优势度指数的最优模型环境因子光滑函数拟合结果。实点表示观测的优势度指数, 实线为模型预测的拟合曲线, 虚线表示模型预测的 $95 \%$ 置信区间。纵坐标为环境因子的光滑函数, 表示其对Simpson优势度指数的影响程度。

Fig. 4 Results of GAM analysis on Simpson dominance index. Dot represents observed dominance index. Solid line represents the predicted 95\% fitting curves by model. Dashed lines represent confident intervals of predicted diversity. Ordinate is smooth function for environmental variables, represents their impact on Simpson dominance index.

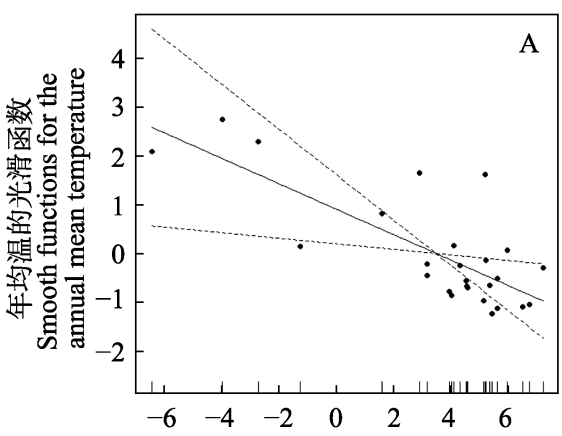

年均温 Annual mean temperature $\left({ }^{\circ} \mathrm{C}\right)$
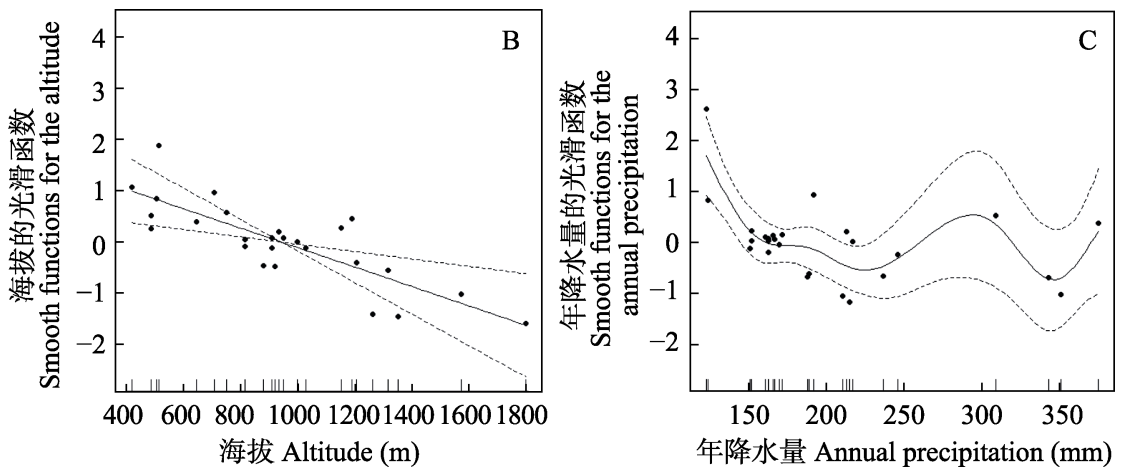

图5 丰富度的最优模型环境因子光滑函数拟合结果。实点表示观测的丰富度, 实线为模型预测的拟合曲线, 虚线表示模型预 测的 $95 \%$ 置信区间。纵坐标为环境因子的光滑函数, 表示其对丰富度的影响程度。

Fig. 5 Results of GAM analysis on richness. Dot represents observed richness. Solid line represents the predicted fitting curves by model. Dashed lines represent 95\% confident intervals of predicted diversity. Ordinate is smooth function for environmental variables, represents their impact on richness.

\section{4 讨论}

\section{1 阿勒泰地区爬行动物的区系多样性}

马勇(1981a)、向礼陔和黄人金金(1986)、黄人金金 等(1986)、谷景和及高行宜(1991)通过对阿尔泰山、 天山及大兴安岭兽类和鸟类地理分布的研究, 认为 阿尔泰山与天山相似度较高, 而与同纬度的大兴安 岭相似度较低。马勇(1981b)和马勇等(1987)将阿尔 泰山地区划归为欧洲-西伯利亚亚界阿尔泰-萨彦 岭区, 并单独列为阿尔泰亚区。张荣祖(2011)为避免 对面积不大的过渡地区另立高级系统的层次, 在修 订的《中国动物地理》中将其划归为蒙新区，但同 时强调其独特性。时否等(2002)根据以往动物地理 区划的研究成果, 结合爬行动物的具体情况, 将新
疆爬行动物的地理区划进一步细划为 4 个亚区 9 个 省。本文基于阿尔泰山分布有典型的泰加林区爬行 动物一极北蛙(Vipera berus), 准噶尔盆地分布以中 亚型为主，采纳马勇(1981b)和时䂞等(2002)的意 见。

阿勒泰地区涉及到阿尔泰山地省及准噶尔盆 地省两省，以阿尔泰山为分界线，其中阿尔泰山地 省单独划为 1 个一级区 (阿尔泰-萨彦岭区)、 1 个二级 亚区(阿尔泰亚区)。故阿勒泰地区南北差异较明显: (1)北部阿尔泰山地省区域以古北型为主，兼有中亚 型成分，古北型占 $57.14 \%$ ，中亚型占 $42.86 \%$; (2)南 部准噶尔盆地省区域中亚型占绝对优势，占 92.31\%。

除南北山地一盆地省的差异外，阿勒泰地区的 
地形组合东西分布也不同。以乌仓古湖为中心, 东 侧为山地接平原(阿尔泰山-山前丘陵平原, 额尔齐 斯河、乌伦古河河间平原, 乌伦古河以南平原), 西 侧为两山夹一谷(阿尔泰山-额尔齐斯河谷-萨吾尔 山，其间散布有科克森断块山)。全区地势呈北部山 脉地区西高东低, 南部丘陵平原东高西低。从整体 上看，阿勒泰地区东部区域内爬行动物均为中亚型， 西部区域中亚型较多, 占 $54.55 \%$, 古北型占 $45.45 \%$ 。东南部荒漠地区爬行动物均为中亚型; 西 南部丘陵平原区域同样以中亚型为主, 兼有古北型 成分，中亚型占62.5\%，古北型占 $37.5 \%$; 东北部山 脉地区爬行动物均为中亚型; 西北部山脉地区则以 古北型为主，占 $60 \%$, 中亚型占 $40 \%$ 。阿勒泰地区西 北部分布的极北蛏、捷蚚蜴(Lacerta agilis)和胎蚚 (Zootoca vivipara) 等古北型爬行动物分布区域可延 伸至欧洲(Cui et al, 2016)。东部分布的奇台沙蚚 (Phrynocephalus grumgrzimailoi)、新疆岩蚚(Laudakia stoliczkana)等中亚型物种主要分布在准噶尔界 山以东。表现出阿勒泰地区作为欧洲西伯利亚区与 中亚区的过渡地区作用。

\section{2 阿勒泰地区爬行动物的海拔分布格局}

物种丰富度沿空间梯度变化的格局及其成因 机制一直是生态学研究中的重要议题(Wang et al, 2007)。本研究显示阿勒泰地区爬行动物物种丰富度 随海拔分布呈波动的递减格局，该结果与Rahbek (1995)、Guo等(2013)的结果(中峰分布格局占多数) 不同, 也与秦岭地区爬行动物物种丰富度的分布格 局(中峰分布格局)不同(郑智等, 2014b), 但与白水 江自然保护区爬行动物物种丰富度格局(递减模式) 相似(郑智等, 2014a), 表明了该地区爬行动物分布 的独特性。

\section{3 阿勒泰地区爬行动物的多样性与环境因子的} 关系

栖息地环境因子(如年均温、相对湿度、年降水 量、海拔和植被类型等)梯度往往对爬行动物多样性 及其空间分布具有显著影响(Carpio et al, 2016; Barrows et al, 2016; Brown et al, 2016)。本研究表明, 年 均温和海拔对阿勒泰地区爬行动物多样性具有显 著影响。

许多研究表明, 爬行类多样性受到海拔的影响 显著(Fu et al, 2006; Chettri et al, 2010; 郑智等, 2014a), 且海拔作为小气候变化的重要原因
(Forcella \& Harvey, 1983; Wilson et al, 1992), 通常 可作为其他环境因子(如年均温、年降水量和植被类 型)的替代指标(Richerson \& Lum, 1980; Sinervo et al, 2010)。

大多数学者认为年均温是影响爬行动物海拔 多样性的重要因素(Kiester, 1971; Schall \& Pianka, 1978; Currie, 1991; Hawkins et al, 2003; Whittaker et $\mathrm{al}$, 2007; McCain, 2010)。这是因为作为外温动物的 爬行动物, 主要通过阳光照射来调节体温, 并以此 维持自己的新陈代谢及生理活动(Porter \& Gates, 1969)。在大尺度的生物多样性分布格局中，温度通 常被认为与多样性呈正比关系(Hawkins et al, 2003; Evans et al, 2005; Storch et al, 2005), 而在本研究中, 阿勒泰地区爬行动物的多样性指数、优势度指数、 丰富度均与年均温呈现线性反比, 即随着年均温的 升高, 多样性呈现下降趋势。可能是由于高温地区, 鸟类、哺乳类的多样性也较高(McCain, 2009; Luo et al, 2012; Hu et al, 2017), 同时在阿勒泰地区，部分 年均温较高地区为低降水量、低云层盖度、稀少的 植物盖度的干旱地区，天敌与干旱地区的环境限制 了部分爬行动物的分布。另一方面，低温度区域多 为海拔较高, 且降水量多的山地地区, 植被盖度高, 天敌少。

在区域或全球尺度的研究证实，水分与两栖动 物物种多样性的相关性更强(Fu et al, 2006; Buckley \& Jetz, 2007; Qian et al, 2007), 与爬行动物物种多 样性的相关性则弱于年均温的相关性(Qian et al, 2007; McCain, 2010)。在本次研究中，单变量与双变 量方面, 除了丰富度, 年均温的解释力、AIC值与相 关性均强于年降水量。这或许也是年均温进入了所 有多样性的最优模型，而年降水量未进入优势度最 优模型的一个原因(表2)。

除年降水量、年均温等环境因子外, 生物物种 多样性的垂直格局还受其他因子(如人为干扰等)的 影响。关于其他因子对阿勒泰地区爬行动物物种多 样性的海拔分布格局影响, 需要精确的量化数据和 进一步研究。

致谢：感谢新疆阿勒泰地区林业局对野外工作的大 力支持。中国科学院动物研究所王苏盆、姜春燕、 乔慧捷、吴文卉, 中国环境科学研究院吉晟男, 四 
川农业大学刘㻈, 新疆布尔根河狸国家级自然保护 区陈刚参与了野外工作, 在此一并致谢!

\section{参考文献}

Barrows CW, Hoines J, Vamstad MS, Murphy-Mariscal M, Lalumiere K, Heintz J (2016) Using citizen scientists to assess climate change shifts in desert reptile communities. Biological Conservation, 195, 82-88.

Brown JH (1971) Mammals on mountaintops: Nonequilibrium insular biogeography. The American Naturalist, 105, 467-478.

Brown JL, Sillero N, Glaw F, Bora P, Vieites DR, Vences M (2016) Spatial biodiversity patterns of Madagascar's amphibians and reptiles. PLoS ONE, 11, e0144076.

Buckley LB, Jetz W (2007) Environmental and historical constraints on global patterns of amphibian richness. Proceedings of the Royal Society of London B: Biological Sciences, 274, 1167-1173.

Cai B, Wang YZ, Chen YY, Li JT (2015) A revised taxonomy for Chinese reptiles. Biodiversity Science, 23, 365-382. (in Chinese with English abstract) [蔡波, 王跃招, 陈跃英, 李 家堂 (2015) 中国爬行纲动物分类厘定. 生物多样性, 23, 365-382.]

Cao MC, Zhou GS, Weng ES (2005) Application and comparison of generalized models and classification and regression tree in simulating tree species distribution. Acta Ecologica Sinica, 25, 2031-2040. (in Chinese with English abstract) [曹铭昌, 周广胜, 翁恩生 (2005) 广义模型及分 类回归树在物种分布模拟中的应用与比较. 生态学报, 25, 2031-2040.]

Carpio AJ, Oteros J, Tortosa FS, Guerrero-Casado J (2016) Land use and biodiversity patterns of the herpetofauna: The role of olive groves. Acta Oecologica, 70, 103-111.

Chettri B, Bhupathy S, Acharya BK (2010) Distribution pattern of reptiles along an eastern Himalayan elevation gradient, India. Acta Oecologica, 36, 16-22.

Cui SP, Luo X, Chen DQ, Sun JZ, Chu HJ, Li CW, Jiang ZG (2016) The adder (Vipera berus) in Southern Altay Mountains: Population characteristics, distribution, morphology and phylogenetic position. PeerJ, 4, e2342.

Currie DJ (1991) Energy and large-scale patterns of animal and plant-species richness. The American Naturalist, 137, 27-49.

Evans KL, Warren PH, Gaston KJ (2005) Species-energy relationships at the macroecological scale: A review of the mechanisms. Biological Reviews, 80, 1-25.

Forcella F, Harvey SJ (1983) Eurasian weed infestation in western Montana in relation to vegetation and disturbance. Madrono, 30, 102-109.

Fu C, Hua X, Li J, Chang Z, Pu Z, Chen J (2006) Elevational patterns of frog species richness and endemic richness in the Hengduan Mountains, China: Geometric constraints, area and climate effects. Ecography, 29, 919-927.

Gu JH, Gao XY (1991) Studies on the Animals in Xinjiang. Science Press, Beijing. (in Chinese) [谷景和, 高行宜 (1991) 新疆动物研究. 科学出版社, 北京.]

Guo QF, Kelf DA, Sun ZY, Liu HX, Hu LJ, Ren H, Wen J (2013) Global variation in elevational diversity patterns. Scientific Reports, 3, 3007.

Hawkins BA, Field R, Cornell HV, Currie DJ, Guégan JF, Kaufman DM, Kerr JT, Mittelbach GG, Oberdorff T, O’Brien EM, Porter EE, Turner JRG (2003) Energy, water, and broad-scale geographic patterns of species richness. Ecology, 84, 3105-3117.

Hu YM, Jin K, Huang ZW, Ding ZF, Liang JC, Pan XY, Hu HJ, Jiang ZG (2017) Elevational patterns of non-volant small mammal species richness in Gyirong Valley, Central Himalaya: Evaluating multiple spatial and environmental drivers. Journal of Biogeography, 44, 2764-2777.

Huang RX, Xiang LG, Ma J (1986) Study on birds in the Altai of Xinjiang: Feeding habits of birds. Journal of Xinjiang University, 3(4), 79-92. (in Chinese) [黄人金金, 向礼陔, 马 纪 (1986) 新疆阿尔泰山岛类的研究—鸟类的食性. 新疆大学学报, 3(4), 79-92.]

Ji DM, Wen SS (2002) Atlas of Reptiles of China. Henan Science and Technology Press, Zhengzhou. (in Chinese) [季达 明, 温世生 (2002) 中国爬行动物图鉴. 河南科学技术出 版社, 郑州.]

Jiang ZG, Jiang JP, Wang YZ, Zhang E, Zhang YY, Li LL, Xie F, Cai B, Cao L, Zheng GM, Dong L, Zhang ZW, Ding P, Luo ZH, Ding CQ, Ma ZJ, Tang SH, Cao WX, Li CW, Hu HJ, Ma Y, Wu Y, Wang YX, Zhou KY, Liu SY, Chen YY, Li JT, Feng ZJ, Wang Y, Wang B, Li C, Song XL, Cai L, Zang CX, Zeng Y, Meng ZB, Fang HX, Ping XG (2016) Red List of China's Vertebrates. Biodiversity Science, 24, 500-551. (in Chinese and in English) [蒋志刚, 江建平, 王 跃招, 张鹗, 张雁云, 李立立, 谢锋, 蔡波, 曹亮, 郑光 美, 董路, 张正旺, 丁平, 罗振华, 丁长青, 马志军, 汤宋 华, 曹文宣, 李春旺, 胡慧建, 马勇, 吴毅, 王应祥, 周开 亚, 刘少英, 陈跃英, 李家堂, 冯祚建, 王燕, 王斌, 李 成, 宋雪琳, 蔡蕾, 藏春金, 曾岩, 孟智斌, 方红霞, 平晓 鸽 (2016) 中国脊椎动物红色名录. 生物多样性, 24, 500-551.]

Jing XH, Zang RG, Ding Y, Zhang WY, Zhang XP, Bai ZQ, Guo ZJ (2010) Distribution pattern of species diversity along altitudinal gradient in the northern slope of Xiaodonggou in Altai Mountains, Xinjiang. Scientia Silvae Sinicae, 46(1), 23-28. (in Chinese with English abstract) [井 学辉, 藏润国, 丁易, 张炜银, 张新平, 白志强, 郭仲军 (2010) 新疆阿尔泰山小东沟北坡植物多样性沿海拔梯度 分布格局. 林业科学, 46(1), 23-28.]

Kessler M (2000) Elevational gradients in species richness and endemism of selected plant groups in the central Bolivian Andes. Plant Ecology, 149, 181-193.

Kiester AR (1971) Species density of North American 
amphibians and reptiles. Systematic Zoology, 20, 127-137.

Liu YL (2010) Ecological Environment of Altai: Along Xinjiang Kuytun-Beitun Railway. China Environmental Science Press, Beijing. (in Chinese) [刘晏良 (2010) 阿勒泰生态环 境: 新疆奎北铁路沿线. 中国环境科学出版社, 北京.]

Lomolino MV (2001) Elevation gradients of species-density: Historical and prospective views. Global Ecology and Biogeography, 10, 3-13.

Luo ZH, Tang SH, Li CW, Fang HX, Hu HJ, Yang J, Ding JJ, Jiang ZG (2012) Environmental effects on vertebrate species richness: Testing the energy, environmental stability and habitat heterogeneity hypotheses. PLoS ONE, 7, e35514.

Ma Y (1981a) On geographic distribution of the rodents in northern Xinjiang. Acta Zoologica Sinica, 27, 180-188. (in Chinese) [马勇 (1981a) 新疆北部地区啮齿动物地理分布 的研究. 动物学报, 27, 180-188.]

Ma Y (1981b) On the dividing of the zoogeographical regions of rodents of northern Xinjiang. Acta Zoologica Sinica, 27, 395-402. (in Chinese) [马勇 (1981b) 新疆北部地区动物 地理区划的几个问题. 动物学报, 27, 395-402.]

Ma Y, Wang FG, Jin SK, Li SH (1987) Glires (Rodents and Lagomorphs) of Northern Xinjiang and Their Zoogeographical Distribution. Science Press, Beijing. (in Chinese) [马勇, 王逢桂, 金善科, 李思华 (1987) 新疆北部 地区啮齿动物的分类和分布. 科学出版社, 北京.]

McCain CM (2009) Global analysis of bird elevational diversity. Global Ecology and Biogeography, 18, 346-360.

McCain CM (2010) Global analysis of reptile elevational diversity. Global Ecology and Biogeography, 19, 541-553.

Porter WP, Gates DM (1969) Thermodynamic equilibria of animals with environment. Ecological Monographs, 39, 227-244.

Qian H (2010) Environment-richness relationships for mammals, birds, reptiles, and amphibians at global and regional scales. Ecological Research, 25, 629-637.

Qian H, Wang X, Wang S, Li Y (2007) Environmental determinants of amphibian and reptile species richness in China. Ecography, 30, 471-482.

Rahbek C (1995) The elevational gradient of species richness: A uniform pattern? Ecography, 18, 200-205.

Richerson PJ, Lum KL (1980) Patterns of plant species diversity in California: Relation to weather and topography. The American Naturalist, 116, 504-536.

Schall JJ, Pianka ER (1978) Geographical trends in numbers of species. Science, 201, 679-686.

Shi L, Liu GS, Li ZH, Yuan H (2006) An record of Coluber spinalis from Altai Mountain. Journal of Xinjiang Agricultural University, 29(1), 55-57. (in Chinese with English abstract) [时磊, 刘国仕, 李志惠, 原洪 (2006) 阿尔泰山发 现黄脊游蛇. 新疆农业大学学报, 29(1), 55-57.]

Shi L, Zhou YH, Yuan H (2002) Reptile fauna and zoogeographic division of Xinjiang Uygur Autonomous Region. Sichuan Journal of Zoology, 21(3), 152-157. (in Chi- nese) [时否, 周永恒, 原洪 (2002) 新疆维吾尔自治区爬 行动物区系与地理区划. 四川动物, 21(3), 152-157.]

Sinervo B, Mendez-De-La-Cruz F, Miles DB, Heulin B, Bastiaans E, Villagrán-Santa Cruz M, Lara-Resendiz R, Martínez-Méndez N, Calderón-Espinosa ML, Meza-Lázaro RN, Gadsden H, Avila LJ, Morando M, Riva IJDL, Sepulveda PV, Rocha CFD, Ibargüengoytía N, Puntriano CA, Massot M, Lepetz V, Oksanen TA, Chapple DG, Bauer AM, Branch WR, Clobert J, Sites JW (2010) Erosion of lizard diversity by climate change and altered thermal niches. Science, 328, 894-899.

Storch D, Evans KL, Gaston KJ (2005) The species-area-energy relationship. Ecology Letters, 8, 487-492.

Vetaas OR, Grytnes JA (2002) Distribution of vascular plant species richness and endemic richness along the Himalayan elevation gradient in Nepal. Global Ecology and Biogeography, 11, 291-301.

Wang GY, Fan Y, Zhai RX (2005) Distribution and ecology of snakes in Xinjiang. Arid Zone Research, 22, 181-185. (in Chinese with English abstract) [王国英, 范勇, 翟荣仙 (2005) 新疆蛇类的分布及生态特征. 干旱区研究, 22, 181-185.]

Wang Z, Tang Z, Fang J (2007) Altitudinal patterns of seed plant richness in the Gaoligong Mountains, south-east Tibet, China. Diversity and Distributions, 13, 845-854.

Wen ZM, He XH, Jiao F, Jiao JY (2008) The predictive distribution of Stipa bungeana in Yanhe River catchment: GAM model and its application. Acta Ecologica Sinica, 28, 192-201. (in Chinese with English abstract) [温仲明, 赫晓 慧, 焦峰, 焦菊英 (2008) 延河流域本氏针茅 (Stipa bungeana)分布预测: 广义相加模型及其应用. 生态学报, 28, 192-201.]

Whittaker RH (1960) Vegetation of the Siskiyou Mountains, Oregon and California. Ecological Monographs, 30, 279-338.

Whittaker RH, Niering WA (1965) Vegetation of the Santa Catalina Mountains, Arizona: A gradient analysis of the south slope. Ecology, 46, 429-452.

Whittaker RJ, Nogués-Bravo D, Araújo M (2007) Geographical gradients of species richness: A test of the water-energy conjecture of Hawkins et al. (2003) 9 using European data for five taxa. Global Ecology and Biogeography, 16, 76-89.

Wilson JB, Rapson GL, Sykes MT, Watkins AJ, Williams PA (1992) Distributions and climatic correlations of some exotic species along roadsides in South Island, New Zealand. Journal of Biogeography, 19, 183-193.

Wood SN (2017) Generalized Additive Models: An Introduction with R. CRC, London.

Wu YJ, Lei FM (2013) Species richness patterns and mechanisms along elevational gradients. Chinese Journal of Zoology, 48, 797-807. (in Chinese with English abstract) [吴永 杰, 雷富民 (2013) 物种丰富度垂直分布格局及影响机 制. 动物学杂志, 48, 797-807.] 
Wu YJ, Yang QS, Wen ZX, Xia L, Zhang Q, Zhou HM (2013) What drives the species richness patterns of non-volant small mammals along a subtropical elevational gradient? Ecography, 36, 185-196.

Wu YP, Xu H, Li YD, Luo TS, Chen DX, Lin MX (2013) Elevation patterns of tree and shrub species diversity of tropical forests in Jianfengling, Hainan Island. Scientia Silvae Sinicae, 49(4), 16-23. (in Chinese with English abstract) [吴裕 鹏, 许涵, 李意德, 骆土寿, 陈德祥, 林明献 (2013) 海 南尖峰岭热带林乔灌木层物种多样性沿海拔梯度分布格 局. 林业科学, 49(4), 16-23.]

Xiang LG, Huang RX (1986) Study on birds in the Altai of Xinjiang: Distribution of birds. Journal of Xinjiang University, 3(3), 90-106. (in Chinese) [向礼陔, 黄人金金 (1986) 新疆阿尔泰山鸟类的研究—鸟类的分布. 新疆大学学 报, 3(3), 90-106.]

Xu SK, Xiang LG, Huang RX (1980) A new record of lizards from Sinkiang_-Viviparous lizard. Journal of Xinjiang University, (2), 95-96. (in Chinese) [许设科, 向礼陔, 黄人 金金 (1980) 新疆蚚蜴类的新记录——胎生蚚蜴. 新疆大 学学报, (2), 95-96.]

Zhang JT (2004) Quantitative Ecology. Science Press, Beijing. (in Chinese) [张金屯 (2004) 数量生态学. 科学出版社, 北京.]

Zhang RZ (2011) Zoogeography of China. Science Press, Beijing. (in Chinese) [张荣祖 (2011) 中国动物地理. 科学出 版社, 北京.]

Zhao EM, Adler K (1993) Herpetology of China. Society for the Study of Amphibians and Reptiles in cooperation with Chinese Society for the Study of Amphibians and Reptiles, Oxford, Ohio.

Zhao KT (1979) A survey of the classification and distribution of the toad-headed agamids (Phrynocephalus) in China. Acta Scientiarum Naturalium Universitatis Neimongol, 10(2), 111-121. (in Chinese) [赵肯堂 (1979) 中国沙蜊属 的分类和分布研究. 内蒙古大学学报(自然科学版), 10(2), 111-121.]
Zhao KT (1983) Eremias in China. Chinese Journal of Zoology, 18(2), 2-5. (in Chinese) [赵肯堂 (1983) 中国麻蚚属 的初步整理. 动物学杂志, 18(2), 2-5.]

Zhao KT (1997) Toad-headed agamids in China. Chinese Journal of Zoology, 32(1), 15-18. (in Chinese) [赵肯堂 (1997) 中国的沙蚚属研究. 动物学杂志, 32(1), 15-18.]

Zhao KT (1998) Geckoes (Gekkomidae) in western China. Chinese Journal of Zoology, 33(1), 19-24. (in Chinese with English abstract) [赵肯堂 (1998) 中国西部地区的壁虎科 动物研究. 动物学杂志, 33(1), 19-24.]

Zheng Z, Gong DJ, Sun CX (2014a) Elevational pattern of species richness and species range size of herpetofauna in Baishuijiang Nature Reserve: A test of Rapoport's rule. Chinese Journal of Ecology, 33, 537-546. (in Chinese with English abstract) [郑智, 龚大洁, 孙呈祥 (2014a) 白水江 自然保护区两栖爬行动物物种丰富度和种域海拔梯度格 局及对Rapoport法则的验证. 生态学杂志, 33, 537-546.]

Zheng Z, Gong DJ, Sun CX, Li XJ, Li WJ (2014b) Elevational pattern of amphibian and reptile diversity in Qinling Range and explanation. Biodiversity Science, 22, 596-607. (in Chinese with English abstract) [郑智, 龚大洁, 孙呈祥, 李 晓军, 李万江 (2014b) 秦岭两栖、爬行动物物种多样性 海拔分布格局及其解释. 生物多样性, 22, 596-607.]

Zhou YH, Wang GY, Ni YF (1986) A new record and subspecies of tartar sand boa. Journal of Xinjiang Agricultural University, 9(3), 42-45. (in Chinese) [周永恒，王国英，倪 亦非 (1986) 东方沙蟒一新纪录及一新亚种. 新疆农业 大学学报, 9(3), 42-45.]

Zhu Y, Kang MY (2005) Application of ordination and GLM/GAM in the research of the relationship between plant species and environment. Chinese Journal of Ecology, 24, 807-811. (in Chinese with English abstract) [朱源, 康慕谊 (2005) 排序和广义线性模型与广义可加模型在植物种与 环境关系研究中的应用. 生态学杂志, 24, 807-811.]

(责任编委: 江建平 责任编辑: 问文杰)

\section{附录 Supplementary Material}

附录1 阿勒泰地区爬行动物名录

Appendix 1 Checklist of reptiles of Altay Prefecture

http://www.biodiversity-science.net/fileup/PDF/2017194-1.pdf 
陶夏秋, 崔绍朋, 蒋志刚, 初红军, 李娜, 杨道德, 李春旺. 新疆阿勒泰地区爬行动物区系及多样性海拔分布格局. 生物多样 性, 2018, 26 (6): 578-589.

http://www.biodiversity-science.net/CN/10.17520/biods.2017194

附录 1 阿勒泰地区爬行动物名录

Appendix 1 Checklist of reptiles of Altay Prefecture

\begin{tabular}{lllll}
\hline 物种 & 分布型 & 受胁状况 & 海拔范围 & 数据来源 \\
Species & Distribution & Threatened & Altitude range (m) & Data source \\
& & status & & \\
\hline
\end{tabular}

有鳞目 SQUAMATA

I 蜥蜴亚目 Lacertilia

（一）鬛蚚科 Agamidae

1. 旱地沙蚚 Phrynocephalus helioscopus* D

2. 奇台沙蜊 Phrynocephalus grumgrzimailoi ${ }^{*}$ D

3. 变色沙蜊 Phrynocephalus versicolor D

4. 新疆岩蜥 Laudakia stoliczkana* ${ }^{*}$ D

D LC

400-1,600 本研究 This Study

（二）虲蜴科 Lacertidae

5. 胎蜥 Zootoca vivipara

\section{LC}

$400-1,200$

本研究 This Study

D LC

$1,000-1,200$

本研究 This Study

6. 捷蜥蜴 Lacerta agilis ${ }^{*}$

LC

$1,200-1,300$

本研究 This Study

7. 密点麻蜊 Eremias multiocellata

U $\quad$ LC

$1,500-1,600$

本研究 This Study

U LC

$400-1,900$

本研究 This Study

8. 虫纹麻蚚 Eremias vermiculata

D

LC

$500-1,500$

本研究 This Study

9. 快步麻蚚 Eremias velox*

800-900

本研究 This Study

10. 敏麻蚚 Eremias arguta*

$400-1,000$

本研究 This Study

D

500-800

本研究 This Study

(三) 壁虎科 Gekkonidae

11. 隐耳漠虎 Alsophylax pipiens

D

LC

800-900

本研究 This Study 赵肯堂, 1998; 季达

12. 灰中趾虎 Mediodactylus russowii*

D

VU

DI

明和温世生, 2002;

时磊等, 2002

(四) 球趾虎科 Sphaerodactylidae

13. 新疆沙虎 Teratoscincus przewalskii

D

NT

DI

赵肯堂, 1998; 季达 明和温世生, 2002;

时否等, 2002

II 蛇亚目 Serpentes

(五) 蟒科 Boidae

14. 红沙蟒 Eryx miliaris

\section{D}

VU

D VU

15. 东方沙蟒 Eryx tataricus

(六) 游蛇科 Colubridae

16. 白条锦蛇 Elaphe dione

17. 黄脊东方蛇 Orientocoluber spinalis

18. 棋斑水游蛇 Natrix tessellate*

19. 水游蛇 Natrix natrix

（七）蝰科 Viperidae

20. 极北蛏 Vipera berus

21. 东方蝰 Vipera renardi

22. 中介蝮 Gloydius intermedius

D

U

$\mathrm{U}$

D

U

U

D

1,300-1,400

DI

700-800

1,100-1,200

(八) 鳗形蛇科 Lamprophiidae

23. 花条蛇 Psammophis lineolatus
VU

DI

EN

EN

NT

DI

LC

$1,100-2,000$

DI

$1,100-1,200$

DI
本研究 This Study 本研究 This Study

本研究 This Study 本研究 This Study 季达明和温世生, 2002; 时否等, 2002; 王国英等, 2005; 刘 晏良, 2010

王国英等, 2005; 刘 晏良, 2010

本研究 This Study 季达明和温世生, 2002; 时否等, 2002; 王国英等, 2005; 刘 晏良, 2010 本研究 This Study 本研究 This Study 
陶夏秋, 崔绍朋, 蒋志刚, 初红军, 李娜, 杨道德, 李春旺. 新疆阿勒泰地区爬行动物区系及多样性海拔分布格局. 生物多样 性, 2018, 26 (6): 578-589.

http://www.biodiversity-science.net/CN/10.17520/biods.2017194

* 在国内仅分布于新疆。分布型: U: 古北型; D: 中亚型。保护等级: LC: 无危; NT: 近危; VU: 易危; EN: 濒危。海拔范围: DI: 数据不足。

* Limited occurrence in Xinjiang Uyghur Autonomous Region in China. Distribution: U, Palearctic type; D: mid-Asia type. Conservation status: LC, Least concern; NT, Near threatened; VU, Vulnerable; EN, Endangered. Altitude: DI: Data insufficient.

Zhao KT (1998) Geckoes (Gekkomidae) in western China. Chinese Journal of Zoology, 33(1), 19-24. (in Chinese with English abstract) [赵肯堂 (1998) 中国西部地区的壁虎科动物研究. 动物学杂志, 33(1), 19-24.]

Ji DM, Wen SS (2002) Atlas of Reptiles of China. Henan Science and Technology Press, Zhengzhou. (in Chinese) [季达明, 温世生 (2002) 中国爬行动物图鉴. 河南科学技术出版社, 郑州.]

Shi L, Zhou YH, Yuan H (2002) Reptile fauna and zoogeographic division of Xinjiang Uygur Autonomous Region. Sichuan Journal of Zoology, 21(3), 152-157. (in Chinese) [时磊, 周永恒, 原洪 (2002) 新疆维吾尔自治区爬行动物区系与地理区划. 四川动 物, 21(3), 152-157.]

Wang GY, Fan Y, Zhai RX (2005) Distribution and ecology of snakes in Xinjiang. Arid Zone Research, 22, 181-185. (in Chinese with English abstract) [王国英, 范勇, 翟荣仙 (2005) 新疆蛇类的分布及生态特征. 干旱区研究, 22, 181-185.]

Liu YL (2010) Ecological Environment of Altai: Along Xinjiang Kuytun-Beitun Railway. China Environmental Science Press, Beijing. (in Chinese) [刘晏良 (2010) 阿勒泰生态环境: 新疆奎北铁路沿线. 中国环境科学出版社, 北京.] 